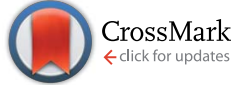

Cite this: Med. Chem. Commun., 2015, 6,357

Received 8th October 2014

Accepted 11th November 2014

DOI: $10.1039 / c 4 m d 00454 j$

www.rsc.org/medchemcomm

\section{Synthetic spirocyclic endoperoxides: new antimalarial scaffolds $\dagger$}

\author{
Margherita Brindisi, ${ }^{\text {abc }}$ Sandra Gemma, ${ }^{\text {abc }}$ Sanil Kunjir, ${ }^{\text {abc }}$ Luisa Di Cerbo, ${ }^{\text {abc }}$ \\ Simone Brogi, ${ }^{\text {abc }}$ Silvia Parapini, ${ }^{\text {acd }}$ Sarah D'Alessandro, ${ }^{\text {acd }}$ Donatella Taramelli, ${ }^{\text {acd }}$ \\ Annette Habluetzel, ${ }^{\text {ce }}$ Sofia Tapanelli, ${ }^{\text {ce }}$ Stefania Lamponi, ${ }^{\text {ab }}$ Ettore Novellino, ${ }^{\text {af }}$ \\ Giuseppe Campiani ${ }^{\star a b c}$ and Stefania Butini ${ }^{\text {abc }}$
}

\begin{abstract}
Here we report the development of a straightforward synthetic procedure for the preparation of spirocyclic endoperoxides as synthetic analogues of the natural product dihydroplakortin. The peroxides presented here are more potent antiplasmodials than dihydroplakortin itself and we proved for the first time their antimalarial activity in vivo.
\end{abstract}

Cyclic peroxides such as 1,2-dioxolanes, 1,2,4-trioxanes and 1,2dioxanes are a class of organic compounds with interesting pharmacological properties and widely represented in nature. Artemisinin (ART) is an endoperoxide-based natural product, which is highly effective against clinically relevant $P$. falciparum strains responsible for human malaria. Currently, the so-called artemisinin-based combination therapies (ACT) are employed as first line treatment in most malaria endemic countries, adhering to WHO recommendations. ${ }^{1-3}$ However, lower susceptibility to artemisinins is being reported from highly malaria endemic regions. ${ }^{4}$ So, novel peroxides characterized by different structural features could delay the potential selection of P. falciparum resistant strains. ${ }^{5}$ Moreover, the cost associated with the extraction of this drug or with synthetic precursors from natural sources prompted researchers to develop synthetic peroxides as low-cost alternatives to ART. ${ }^{6}$

For several years we have been engaged in the design of suitable synthetic strategies for the preparation of antimalarial endoperoxides..$^{7-10}$ In particular we performed the first stereoselective synthesis of 9,10-dihydroplakortin (DHP, 1, Fig. 1), ${ }^{10} \mathrm{a}$ natural product endowed with interesting antiplasmodial

${ }^{a}$ European Research Centre for Drug Discovery and Development (NatSynDrug), University of Siena, via Aldo Moro 2, 53100, Siena, Italy. E-mail: gemma@unisi.it; campiani@unisi.it

${ }^{b}$ Dip. di Biotecnologie, Chimica e Farmacia, University of Siena, via Aldo Moro 2, 53100, Siena, Italy

'Centro Interuniversitario di Ricerche sulla Malaria (CIRM), University of Perugia, Perugia, Italy

${ }^{d}$ Dip. di Scienze Farmacologiche e Biomolecolari, Università di Milano, Via Pascal 36, 20133 Milan, Italy

${ }^{e}$ School of Pharmacy, University of Camerino, Piazza Cavour 19F, 62032 Camerino, Italy

${ }^{f}$ Dip. di Farmacia, University of Naples Federico II, Via D. Montesano 49, 80131 Naples, Italy

$\dagger$ Electronic supplementary information (ESI) available: Scheme S1, Fig. S1 and experimental details. See DOI: 10.1039/c4md00454j properties. ${ }^{11} \mathrm{We}$ also reported the development of novel endoperoxides as synthetic analogues of DHP characterized by a bicyclic tetrahydrofuro[2,3-c][1,2]dioxane core. The synthetic peroxide 2 (Fig. 1) was the most potent compound of the series and showed higher antiplasmodial potency than dihydroplakortin. The major limitation of these analogues was their synthesis as an inseparable mixture of diastereoisomers. ${ }^{7}$ The structure-activity relationships (SARs) for this class of compounds were rationalized on the basis of the mechanism of action proposed for ART.

Although the mechanism of action of ART is still debated, ${ }^{12}$ it seems that the peroxide bond is activated within the food vacuole of the parasite, a specialized organelle accommodating the hydrolysis of hemoglobin, a necessary source of amino acids for the parasites. During this process, free Fe(II)-heme is
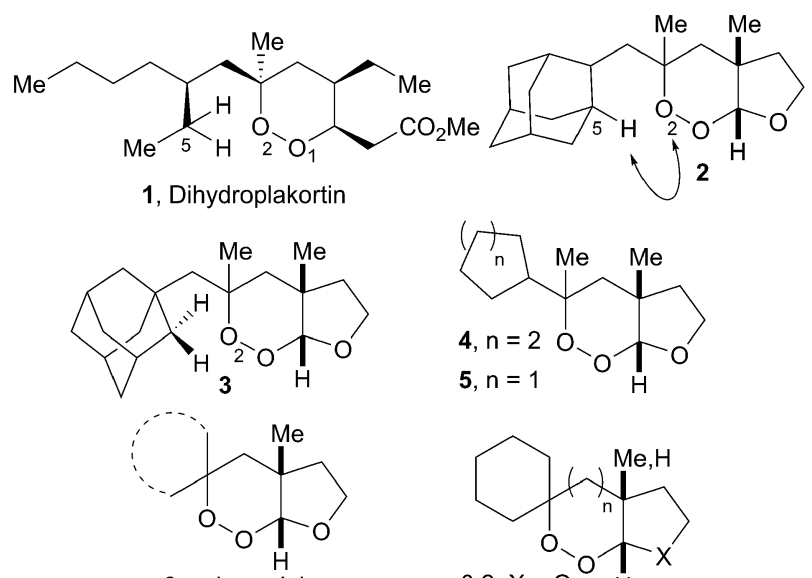

6, spirocyclohexane

7, spirocyclopentane

8, spiroadamantane

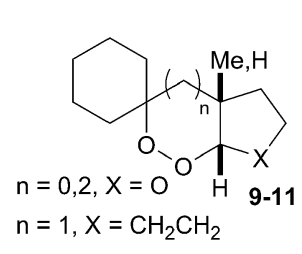

Fig. 1 Structure of reference ( 1 and 2 ) and title (3-11) endoperoxides. 
released and reacts with the peroxide bond of ART to form an O-centered radical, that probably undergoes a $1,5-\mathrm{H}$ shift to form a highly toxic C-centered radical, ${ }^{13,14}$ ultimately responsible for the antiplasmodial activity. The formation of $\mathrm{C}$ centered radicals has also been proposed for several synthetic endoperoxides, comprising DHP. ${ }^{15-17}$ For our synthetic peroxides, we found that subtle modifications of the substituent at $\mathrm{C} 3$, affecting the distance between the $\mathrm{C} 5$ of the lateral chain and the $\mathrm{O} 2$ of the peroxide bridge $\left(\mathrm{C}_{5}-\mathrm{O}_{2}\right.$ distance $<3 \AA$ for optimal activity), had a strong impact on the antiplasmodial potency, in line with the mode of action of ART and DHP. ${ }^{7}$ As a continuation of our previous work, we were interested in developing suitable synthetic strategies aimed at modifying the lateral chain at $\mathrm{C} 3$ of the bicyclic skeleton (3-8) and the size of the rings forming the bicyclic system (9-11) reducing the number of chiral centers. In particular, we were interested in the synthesis of spiro-derivatives 6-8 that lack the stereogenic center at $\mathrm{C} 3$ and represent a further simplification of this class of compounds.

As described in Scheme 1, a three-step reaction protocol was employed for the assembly of the bicyclic core starting from olefin intermediates 12a-d and 13a-c. The first step of the protocol consisted of the Mukaiyama peroxysilylation reaction $^{18,19}$ of the double bond of intermediates 12a-d and 13a-c to afford peroxides 14a-d and 15a-c, respectively. The Mukaiyama reaction proceeds regioselectively at the more substituted carbon of the double bond. Subsequently the lactone functionality was reduced to the corresponding lactol by using diisobutylaluminum hydride (DIBAL). Finally, trimethylsilyl triflate (TMSOTf)-promoted simultaneous deprotection and cyclization of the resulting lactols afforded the cyclised endoperoxides 3-5, isolated as inseparable mixtures of diastereoisomers, and spiroperoxides 6-9 obtained as racemates. Following a slightly modified protocol, the synthesis of

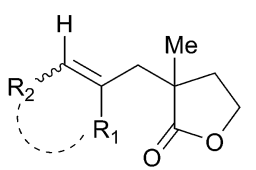

12a, $R_{1}=M e, R_{2}=1$-Ada 12b, $\mathrm{R}_{1}=\mathrm{CyHex}, \mathrm{R}_{2}=\mathrm{H}$ 12c, $R_{1}=$ CyPent, $R_{2}=H$ 12d, $\mathrm{R}_{1}, \mathrm{R}_{2}=-\left(\mathrm{CH}_{2}\right)_{4^{-}}^{-}$

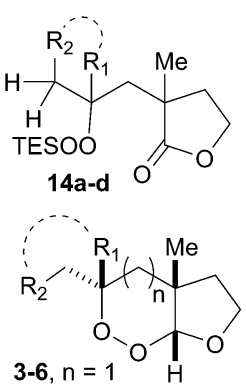
a
Scheme 1 General synthesis of endoperoxides 3-9. [Reaction conditions: (a) $\mathrm{Co}$ (thd) $)_{2}, \mathrm{Et}_{3} \mathrm{SiH}, \mathrm{O}_{2}, \mathrm{t}-\mathrm{BuOOH}$ (5 $\mathrm{M}$ in nonane), 1,2dichloroethane (1,2-DCE), $25^{\circ} \mathrm{C}, 4 \mathrm{~h}$; (b) DIBAL, DCM, $-78^{\circ} \mathrm{C}, 1.5 \mathrm{~h}$; (c) TMSOTf, DCM, $\left.-78^{\circ} \mathrm{C}, 5 \mathrm{~min}\right]$. endoperoxide $\mathbf{1 0}$ is reported in the ESI. $\dagger$ The synthesis of intermediates 12a,d and $\mathbf{1 3 c}$ is described in Scheme 2. 1-Adamantylaldehyde 16a and cyclohexanone $\mathbf{1 6 b}$ were submitted to the Horner-Wadsworth-Emmons olefination reaction to afford the $\alpha, \beta$-unsaturated esters 17a and 17b. DIBAL-mediated reduction of the above mentioned esters $17 \mathbf{a}$ and $\mathbf{1 7} \mathbf{b}$ and of commercially available ester 17c afforded the corresponding primary alcohols that were subsequently converted into iodides 18a-c. While iodides $18 \mathbf{a}$ and $\mathbf{1 8 c}$ were obtained by treatment of alcohols with iodine, triphenylphosphine, and imidazole, iodide $\mathbf{1 8 b}$ could not be obtained by using the same protocol. 18b was instead obtained by treatment of the alcohol precursor with potassium iodide in the presence of boron trifluoride. Iodides 18a-c were next used to alkylate lactone 19 using lithium hexamethyldisilylamide (LiHMDS) as the base to afford 12a,d and 13c. Intermediates $12 \mathbf{b}$ and 12c, bearing cyclohexyl and cyclopentyl substituents, were prepared as reported in Scheme 3. The synthesis of an analogue bearing an adamantylradical at the same position was also attempted without success. Accordingly, cyclohexyl and 1-adamantyl derivatives 20a,b were treated with cerium chloride as a Lewis acid and sodium hypochlorite as the oxidizing agent to afford chloromethyl derivatives $\mathbf{2 1 a} \mathbf{b}$ in reasonable yields. Intermediates 21a,b were in turn converted into the corresponding iodides 22a,b. Intermediate 22c was synthesized starting from 25, in turn prepared following a different synthetic approach by reacting Grignard reagent 23, formed in situ, with propargyl alcohol 24. ${ }^{20}$ The resulting primary alcohol 25 was then converted to 22c via a mesyl ester intermediate that was sonicated in the presence of lithium iodide to afford the desired iodide 22c in good overall yield. Iodides 22a-c were used as alkylating agents for the enolate of lactone 19. While 22a,c smoothly furnished the corresponding alkylation products, the same reaction performed with the adamantyl derivative 22b failed, probably due to its higher steric hindrance. For the synthesis of intermediates 13a and 13b (Scheme 4), alcohol intermediates $27 \mathbf{a}$ and $27 \mathbf{b}$, in turn obtained by aldol condensation of aldehydes $26 \mathbf{a}$ and $26 \mathbf{b}$ with 19 in the presence of lithium diisopropylamide (LDA), were dehydrated to the corresponding

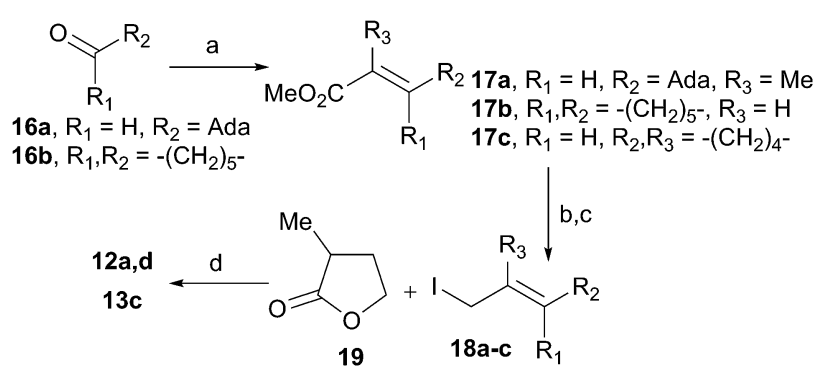

Scheme 2 Synthesis of intermediates 12a,d and 13c. [Reaction conditions: (a) triethyl 2-phosphonopropionate (for 17a), or triethyl phosphonoacetate (for $17 \mathrm{~b}$ ), $\mathrm{NaH}, \mathrm{THF}, 0{ }^{\circ} \mathrm{C}, 1 \mathrm{~h}$, then $25^{\circ} \mathrm{C}, 2 \mathrm{~h}$; (b) DIBAL, DCM, $-78{ }^{\circ} \mathrm{C}, 1.5 \mathrm{~h}$; (c) $\mathrm{I}_{2}, \mathrm{PPh}_{3}$, imidazole, $1: 3 \mathrm{MeCN} / \mathrm{Et}_{2} \mathrm{O}$, $0{ }^{\circ} \mathrm{C}, 30 \mathrm{~min}$ (from $17 \mathrm{a}$ and $17 \mathrm{c}$ ) or $\mathrm{KI}, \mathrm{BF}_{3} \cdot \mathrm{Et}_{2} \mathrm{O}$, dioxane, $25^{\circ} \mathrm{C}, 3 \mathrm{~h}$ (from 17b); (d) (i). 19, LiHMDS, THF, $-78^{\circ} \mathrm{C}, 30 \mathrm{~min}$; (ii). $17 \mathrm{a}-\mathrm{C},-78^{\circ} \mathrm{C}$, $30 \mathrm{~min}$, then $25^{\circ} \mathrm{C}, 2 \mathrm{~h}$. 


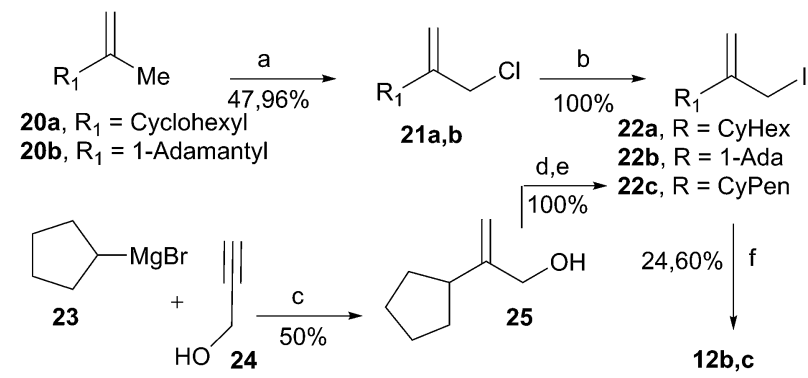

Scheme 3 Synthesis of intermediates $12 \mathrm{~b}$ and $12 \mathrm{c}$. [Reaction conditions: (a) $\mathrm{CeCl}_{3} \cdot 7 \mathrm{H}_{2} \mathrm{O}, 10-13 \% \mathrm{NaOCl}, 1: 1 \mathrm{DCM} / \mathrm{H}_{2} \mathrm{O}, 25^{\circ} \mathrm{C}, 14 \mathrm{~h}$; (b) Nal, acetone, $25^{\circ} \mathrm{C}, 18 \mathrm{~h}$; (c) Cul, THF, $25^{\circ} \mathrm{C} 24 \mathrm{~h}, 80^{\circ} \mathrm{C}, 5 \mathrm{~h}$; (d) $\mathrm{MsCl}$, $\mathrm{Et}_{3} \mathrm{~N}, \mathrm{Et}_{2} \mathrm{O}, 0{ }^{\circ} \mathrm{C}, 12 \mathrm{~h}$; (e) Lil, $\mathrm{Et}_{2} \mathrm{O}$, sonication, $25^{\circ} \mathrm{C}, 3 \mathrm{~h}$; (f) (i). 19 , LiHMDS, THF, $-78^{\circ} \mathrm{C}, 30 \mathrm{~min}$; (ii) $22 \mathrm{a}$ and $22 \mathrm{c},-78^{\circ} \mathrm{C}, 30 \mathrm{~min}$, then 25 $\left.{ }^{\circ} \mathrm{C}, 2 \mathrm{~h}\right]$.

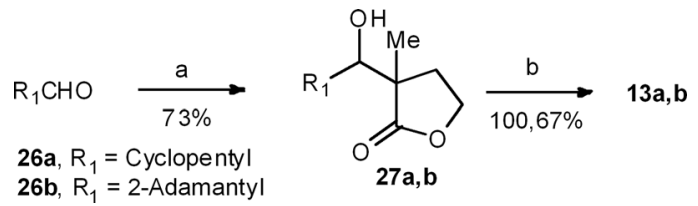

Scheme 4 Synthesis of intermediates $13 \mathrm{a}$ and $13 \mathrm{~b}$. [Reaction conditions: (a) $19, \mathrm{LDA},-78^{\circ} \mathrm{C}, 20 \mathrm{~min}$, then $25^{\circ} \mathrm{C}, 8 \mathrm{~h}$; (b) SOCl , pyridine, $\left.25^{\circ} \mathrm{C}, 2 \mathrm{~h}\right]$.

olefins. Finally, dioxolane rac-11 was synthesized as described in Scheme 5. The carbonyl group of the commercially available ketone 28 was reduced using sodium borohydride and the double bond was hydroperoxysilylated to $\mathbf{2 9}$ under Mukaiyama reaction conditions. Treatment of $\mathbf{2 9}$ with methanesulfonyl chloride in the presence of triethylamine directly afforded the cyclization product rac-11.

The antiplasmodial activity of the novel endoperoxides 3-11 was tested against two laboratory $P$. falciparum strains, the chloroquine-sensitive (CQ-S) D10 and the chloroquine-resistant (CQ-R) W2, according to the described procedures. ${ }^{7}$ The resulting $\mathrm{IC}_{50}$ values are reported in Table 1.

To understand the modulation of antiplasmodial potency observed for the synthesized compounds, we in depth analyzed the interaction of the peroxide moiety of compounds 4-11 with $\mathrm{Fe}(\mathrm{II})$-heme (which is the first and the key step for the formation of the toxic radical species) by molecular docking analysis employing Glide software, after structure optimization was performed by using $a b$ initio calculation employing the Jaguar

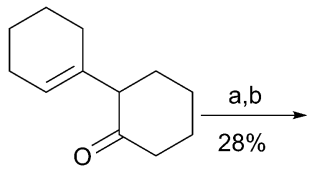

28

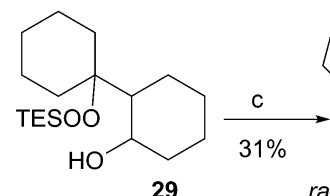

29

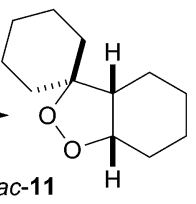

Scheme 5 Synthesis of $\mathrm{rac}$-11. [Reaction conditions: (a) $\mathrm{NaBH}_{4}, \mathrm{EtOH}$ $\mathrm{O}^{\circ} \mathrm{C}, 1 \mathrm{~h}$, then $25^{\circ} \mathrm{C}, 12 \mathrm{~h}$; (b) $\mathrm{Co}$ (thd) $)_{2}, \mathrm{Et}_{3} \mathrm{SiH}, \mathrm{O}_{2}, t-\mathrm{BuOOH}$ (5 M in nonane), 1,2-DCE, $25^{\circ} \mathrm{C}, 4 \mathrm{~h}$; (c) $\mathrm{MsCl}, \mathrm{Et}_{3} \mathrm{~N}, \mathrm{DCM}, 0{ }^{\circ} \mathrm{C}, 2 \mathrm{~h}$ ]. software. ${ }^{22,23}$ The endoperoxides reported here have been produced and tested as mixtures of diastereoisomers (3-5) or as racemates (6-11), while docking studies were performed for each enantiomer. As expected, heme is unable to discriminate between enantiomers ${ }^{24}$ and no differences in the binding mode of each enantiomeric couple were observed. Based on our molecular docking calculations, we found a good correlation between the distance of oxygen atoms from the reactive heme iron center and the antimalarial activity (Table 1). In fact, the compounds that display a larger distance of the peroxide moiety from the iron center such as compounds 6, 9-11 were found less

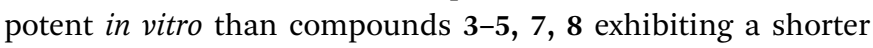
distance. For example, peroxide 4 (one of the most active compounds in the set) displays a very short distance between the peroxide oxygen atoms and the iron center (Table 1) and both atoms could be able to coordinate the heme iron. In contrast, the inactive analogue 9 does not possess the appropriate distance to interact with heme iron.

For comparison, distances calculated for the reference compounds ART and DHP are also in good agreement with a correct interaction with heme (Table 1 and Fig. S1 in the ESI $\uparrow$ ). Also the free-binding energy ${ }^{21}\left(\Delta G_{\text {bind }}\right)$ calculated for all complexes (Table 1), displayed a good correlation with antiplasmodial potency, being around $-20 \mathrm{kcal} \mathrm{mol}^{-1}$ for inactive compounds (9), comprised between -20 and $-25 \mathrm{kcal} \mathrm{mol}^{-1}$ for compounds in the micromolar range $(6,10,11)$, and $<-25 \mathrm{kcal}$ $\mathrm{mol}^{-1}$ for compounds in the low micromolar range $(\mathbf{1}, \mathbf{3 - 5}, \mathbf{7}, \mathbf{8})$. It is worth noting that ART presents a calculated $\Delta G_{\text {bind }}$ well below the value found for the spiroperoxides presented here, consistent with its nanomolar antiplasmodial potency. Compound 8, displaying an estimated $\Delta G_{\text {bind }}$ of $-30.69 \mathrm{kcal}$ $\mathrm{mol}^{-1}$, is the most potent plakortin-related endoperoxide described to date. ${ }^{11}$ Accordingly, both epimers of compounds 4 and 5 (Fig. 2A-D) interact with heme in a similar fashion. However, the larger steric hindrance of the cyclohexyl ring of $\mathbf{4}$ with respect to the cyclopentyl ring of 5 results in a stronger hydrophobic interaction with heme for 4 . For the couple of analogues 6 and 7 (Fig. 3A and B), the steric hindrance of the cyclohexyl ring physically hampers the accommodation of $\mathbf{6}$ for a strong interaction with $\mathrm{Fe}(\mathrm{II})-$ heme (Fig. 2A), while the cyclopentyl ring of 7 (Fig. 3B) has a reduced steric hindrance and is well tolerated allowing both $\mathrm{O}_{2}$ and $\mathrm{O}_{1}$ of the peroxide system to interact with Fe(II)-heme. Docking studies (Fig. 2 and 3) highlighted that subtle differences in the structure of the peroxides and in particular of the size and shape of their side chains are responsible for a fine-tuning of the antiplasmodial activity. On the other hand, the bulky adamantane ring $(\mathbf{8}$, Fig. $3 \mathrm{C})$ is able to maximize hydrophobic interactions with the planar protoporphyrin-IX ring while maintaining a correct orientation of both the peroxide oxygens for their interaction with $\mathrm{Fe}(\mathrm{II})$-heme, thus resulting in an overall improved $\Delta G_{\text {bind }}$ and, as a consequence, higher antiplasmodial potency. Finally, the seven-membered ring of compound $\mathbf{9}$ (Fig. 3D) is not tolerated since it hampers a favourable conformation for reaching the right distance to the iron atom contained in the protoporphyrin-IX ring (Fig. 3D). Spiroperoxide 8, the most potent antiplasmodial agent of the series, was submitted to a preliminary in vivo evaluation in the 
Table 1 Antiplasmodial activity, calculated $\mathrm{O}_{1}, \mathrm{O}_{2} \cdots \mathrm{Fe}(॥)$-heme distances ${ }^{b}$, and $\Delta G_{\text {bind }}\left(\text { kcal mol }^{-1}\right)^{c}$

\begin{tabular}{|c|c|c|c|c|c|c|}
\hline \multirow[b]{2}{*}{ Cpd } & \multirow[b]{2}{*}{ Structure } & \multirow{2}{*}{$\frac{\mathrm{D} 10}{\mathrm{IC}_{50}(\mu \mathrm{M})^{a}}$} & W2 & \multirow[b]{2}{*}{$\mathrm{O}_{2}-\mathrm{Fe}^{b}$} & \multirow[b]{2}{*}{$\mathrm{O}_{1}-\mathrm{Fe}^{b}$} & \multirow[b]{2}{*}{$\Delta G_{\text {bind }}^{c}\left(\mathrm{kcal} \mathrm{mol}^{-1}\right)$} \\
\hline & & & & & & \\
\hline 3 & & 0.85 & 0.39 & $\begin{array}{l}2.27(\mathrm{E} 1)^{d} \\
2.21(\mathrm{E} 2)^{e}\end{array}$ & $\begin{array}{l}2.13(\mathrm{E} 1) \\
2.16(\mathrm{E} 2)\end{array}$ & $\begin{array}{l}-29.33 \\
-30.48\end{array}$ \\
\hline 4 & & 0.39 & 0.14 & $\begin{array}{l}2.25(\mathrm{E} 1) \\
2.20(\mathrm{E} 2)\end{array}$ & $\begin{array}{l}2.22(\mathrm{E} 1) \\
2.22(\mathrm{E} 2)\end{array}$ & $\begin{array}{l}-30.28 \\
-29.25\end{array}$ \\
\hline 5 & & 1.2 & 0.8 & $\begin{array}{l}2.31(\mathrm{E} 1) \\
2.34(\mathrm{E} 2)\end{array}$ & $\begin{array}{l}2.24(\mathrm{E} 1) \\
2.32(\mathrm{E} 2)\end{array}$ & $\begin{array}{l}-27.30 \\
-26.55\end{array}$ \\
\hline 6 & & 5.3 & 1.1 & 3.89 & 3.03 & -23.82 \\
\hline 7 & & 0.84 & 0.47 & 2.81 & 2.24 & -28.43 \\
\hline 8 & & 0.61 & 0.16 & 2.18 & 2.16 & -30.69 \\
\hline 9 & & $>20$ & $>17.0$ & 3.36 & 3.90 & -19.76 \\
\hline 10 & & 8.5 & $>25$ & 2.40 & 2.99 & -24.46 \\
\hline 11 & & 7.2 & 3.2 & 2.34 & 3.22 & -22.64 \\
\hline 1 (ref. 7) & & 0.86 & 0.44 & 2.20 & 2.27 & -31.04 \\
\hline ART & & 0.029 & 0.012 & 2.14 & 2.10 & -43.13 \\
\hline CQ & & 0.015 & 0.228 & - & - & - \\
\hline
\end{tabular}

${ }^{a} \mathrm{IC}_{50}$ values are the mean of at least three determinations in duplicate. Standard errors were all within $10 \%$ of the mean. ${ }^{b}$ The distances were calculated and reported in $\AA$ by means of the measurement tool implemented in the Maestro graphical interface from the poses obtained by docking calculations. ${ }^{c}$ The binding energy was calculated by means of Prime MM-GSBA. ${ }^{21} d$ E1 $=$ epimer $1: 3 R^{*}, 4 a S^{*}, 7 a R^{*}$. ${ }^{e}$ E2 $=$ epimer 2 : $3 S^{*}, 4 a S^{*}, 7 a R^{*}$.

P. berghei mouse model of malaria using the Peters 4 day test. ${ }^{26}$ After administration of 8 at a daily dose of $100 \mathrm{mg} \mathrm{kg}^{-1}$ (i.p.), mice showed a $72.5 \%$ reduction in parasitaemia. Notably, compound 8 did not elicit, at the concentration used in the in vivo study, any sign of toxicity in mice, consistently with its determined in vitro toxicity against mouse fibroblasts NIH3T3 $\left(\mathrm{TC}_{50}=150 \mu \mathrm{M}\right)$.

In conclusion, we herein presented the development of a straightforward synthetic procedure for the preparation of spiroperoxides as racemic mixtures endowed with antiplasmodial activity against $P$. falciparum CQ-S and CQ-R strains. Being heme an achiral target, compounds were tested as racemates since no difference on antiplasmodial activity for each enantiomer could be expected. ${ }^{\mathbf{2 4}}$ Molecular modelling studies highlighted key molecular features responsible for activity and potency, and will be useful for further optimizing their in vitro potency. Moreover, we have herein for the first time provided evidence that plakortin-derived synthetic analogues do have antimalarial activity in vivo. The straightforward synthetic approach to spirocyclic endoperoxides may pave the way to the development of more potent analogues in vivo. 

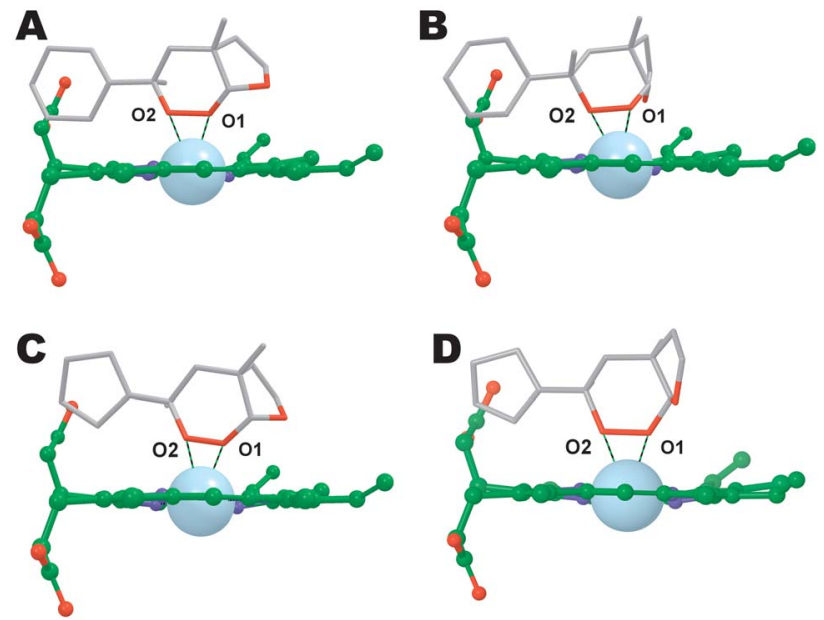

Fig. 2 Docked poses of both epimers of 4 (panels A and B in gray sticks) and 5 (panels $C$ and $D$ ) in complex with heme (green balls and sticks), charged iron was colored cyan and represented by the CPK model. The potential ligand-metal coordination bonds are reported as black-green dotted lines. The picture was generated by Maestro. ${ }^{25}$

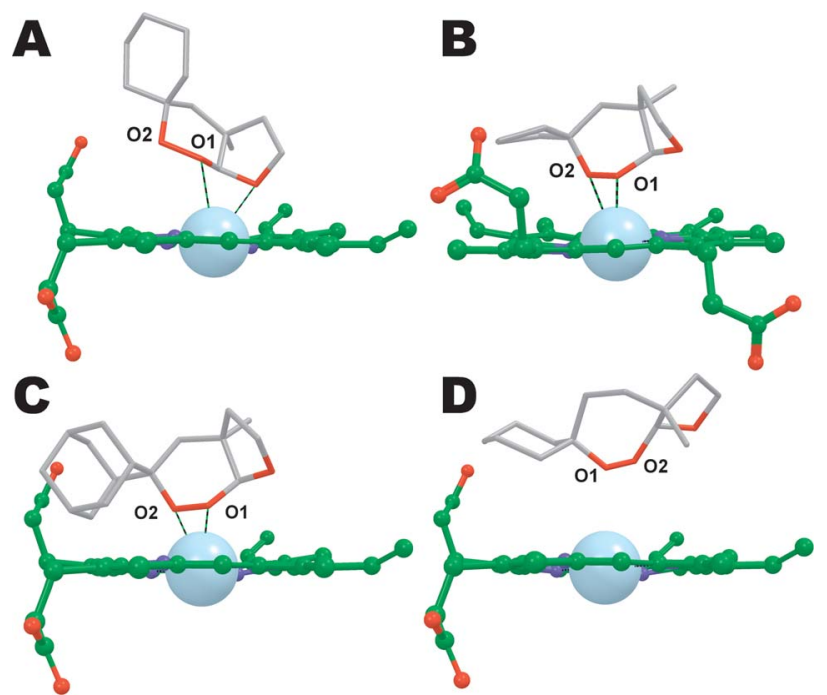

Fig. 3 Docked poses of 6-9 (gray sticks; A, B, C, and D, respectively) in complex with heme (green balls and sticks), charged iron was colored cyan and represented by the CPK model. The potential ligand-metal coordination bonds are reported as black-green dotted lines. The picture was generated by Maestro. ${ }^{25}$

\section{Acknowledgements}

The authors thank MIUR for financial support. S.B. thanks S-IN Soluzioni Informatiche for technical support.

\section{Notes and references}

1 World Health Organization, World Malaria Report, 2013, Geneva.
2 M. Njoroge, N. M. Njuguna, P. Mutai, D. S. Ongarora, P. W. Smith and K. Chibale, Chem. Rev., 2014, DOI: $10.1021 /$ cr500098f.

3 http:/www.who.int/malaria/publications/atoz/9789241500838/ en/, access date: 28/07/2014.

4 E. A. Ashley, M. Dhorda, R. M. Fairhurst, C. Amaratunga, P. Lim, S. Suon, S. Sreng, J. M. Anderson, S. Mao, B. Sam, C. Sopha, C. M. Chuor, C. Nguon, S. Sovannaroth, S. Pukrittayakamee, P. Jittamala, K. Chotivanich, K. Chutasmit, C. Suchatsoonthorn, R. Runcharoen, et al., N. Engl. J. Med., 2014, 371, 411-423.

5 F. Ariey, B. Witkowski, C. Amaratunga, J. Beghain, A. C. Langlois, N. Khim, S. Kim, V. Duru, C. Bouchier, L. Ma, P. Lim, R. Leang, S. Duong, S. Sreng, S. Suon, C. M. Chuor, D. M. Bout, S. Menard, W. O. Rogers, B. Genton, et al., Nature, 2014, 505, 50-55.

6 J. L. Vennerstrom, S. Arbe-Barnes, R. Brun, S. A. Charman, F. C. Chiu, J. Chollet, Y. Dong, A. Dorn, D. Hunziker, H. Matile, K. McIntosh, M. Padmanilayam, J. Santo Tomas, C. Scheurer, B. Scorneaux, Y. Tang, H. Urwyler, S. Wittlin and W. N. Charman, Nature, 2004, 430, 900-904.

7 S. Gemma, S. Kunjir, S. S. Coccone, M. Brindisi, V. Moretti, S. Brogi, E. Novellino, N. Basilico, S. Parapini, D. Taramelli, G. Campiani and S. Butini, J. Med. Chem., 2011, 54, 59495953.

8 S. Gemma, F. Marti, E. Gabellieri, G. Campiani, E. Novellino and S. Butini, Tetrahedron Lett., 2009, 50, 5719-5722.

9 S. Gemma, S. Kunjir, M. Brindisi, E. Novellino, G. Campiani and S. Butini, Tetrahedron Lett., 2013, 54, 1233-1235.

10 S. Gemma, E. Gabellieri, S. S. Coccone, F. Marti, O. Taglialatela-Scafati, E. Novellino, G. Campiani and S. Butini, J. Org. Chem., 2010, 75, 2333-2340.

11 E. Fattorusso, S. Parapini, C. Campagnuolo, N. Basilico, O. Taglialatela-Scafati and D. Taramelli, J. Antimicrob. Chemother., 2002, 50, 883-888.

12 S. Krishna, S. Pulcini, C. M. Moore, B. H. Teo and H. M. Staines, Trends Pharmacol. Sci., 2014, 35, 4-11.

13 J. N. Cumming, P. Ploypradith and G. H. Posner, Adv. Pharmacol., 1997, 37, 253-297.

14 G. H. Posner, J. N. Cumming, P. Ploypradith and H. O. Chang, J. Am. Chem. Soc., 1995, 117, 5885-5886.

15 C. W. Jefford, Curr.Top. Med. Chem., 2012, 12, 373-399.

16 O. Taglialatela-Scafati, E. Fattorusso, A. Romano, F. Scala, V. Barone, P. Cimino, E. Stendardo, B. Catalanotti, M. Persico and C. Fattorusso, Org. Biomol. Chem., 2010, 8, 846-856.

17 F. Bousejra-El Garah, M. H. Wong, R. K. Amewu, S. Muangnoicharoen, J. L. Maggs, J. L. Stigliani, B. K. Park, J. Chadwick, S. A. Ward and P. M. O'Neill, J. Med. Chem., 2011, 54, 6443-6455.

18 S. Isayama and T. Mukaiyama, Chem. Lett., 1989, 573-576.

19 P. M. O'Neill, S. Hindley, M. D. Pugh, J. Davies, P. G. Bray, B. K. Park, D. S. Kapu, S. A. Ward and P. A. Stocks, Tetrahedron Lett., 2003, 44, 8135-8138.

20 F. Barile, M. Bassetti, A. D'Annibale, R. Gerometta and M. Palazzi, Eur. J. Org. Chem., 2011, 6519-6526. 
21 P. D. Lyne, M. L. Lamb and J. C. Saeh, J. Med. Chem., 2006, 24 C. W. Jefford, Drug Discovery Today, $2007,12,487-495$.

49, 4805-4808.

22 Glide, version 5.7, Schrödinger, LLC, New York, NY, 2011.

23 Jaguar, version 7.8, Schrödinger, LLC, New York, NY, 2011.
25 Maestro, version 9.2, Schrödinger, LLC, New York, NY, 2011. 26 D. J. Knight and W. Peters, Ann. Trop. Med. Parasitol., 1980, 74, 393-404. 